\title{
Comprehensive technologies for increase of reliability and energy efficiency of medium capacity PTVM and KVGM hot-water boilers
}

\author{
Rakhimzhan Orumbayev ${ }^{1}$, Andrey Kibarin ${ }^{1}$, Arman Kassimov $^{1}$, Tatyana Khodanova ${ }^{1}$ and Maxim Korobkov ${ }^{1}$ \\ ${ }^{1}$ Non-profit JSC "Almaty University of Power Engineering and Telecommunications", Baitursynov str. 126/1, Almaty, Kazakhstan
}

\begin{abstract}
This article is dedicated to the problems of reliability, long-term thermal capacity and operational efficiency rate of PTVM and KGVM hot-water boilers. Based on the analysis of statistic data, tests, and certain works on increase of efficiency and reliability of PTVM-100 tower hot-water boilers, which were performed in Kazakhstan, it may be said that the reconstruction of PTVM-100 boilers accomplished on CHP was mainly aimed at the increase of reliability while saving the operational efficiency of boilers almost without changes. If the boiler is operating on fuel oil and without periodical washes, then it is possible to achieve consistent operation only under $75 \%$ of the nominal operational load. Structural changes of the PTVM-100 boiler unit offered by authors, along with the increase of operational reliability on fuel oil and it's thermal capacity, allow increasing boiler's efficiency rate up to $91-92 \%$ if it is operated under nominal load and using fuel oil. Structure the new KV-GM 55 hot-water boiler with horizontal design includes the two-row bi-radiated screen wrapping around the furnace and the new arrangement of convective packs, which are now located next to each other, allowed to increase heating characteristics of the boiler significantly due to the intensification of heat exchange and decrease of temperature of gases released from behind of the boiler unit, as well as to increase boiler's efficiency rate up to $92,5 \%$ under nominal load.
\end{abstract}

\section{Introduction}

Nowadays, many medium capacity hot-water boilers with outdated design are operated across the Republic of Kazakhstan and show low efficiency and reliability rates. Overall designs of KV-GM and PTVM hot-water boilers were developed during the middle of the XX century [1, 2]. Many of those currently operated PTVM boilers have exceeded their service life and in order to correspond to the modern ecological and technical requirements, they have to be either replaced or improved. The actual output thermal capacity of PTVM-100 boilers is around 99-105 MW, if operated on gas, and about 70-81 MW, if operated on fuel oil (whereas the calculated value equals to $116 \mathrm{MW}$ ), and these type of boilers have a low efficiency rate of $87-88 \%[3,4,5,6]$. These boilers also emit a sufficient amount of nitrogen oxides contained in exhaust gases, up to $0.5-0.6 \mathrm{~g} / \mathrm{nm}^{3}$, of operated on gas, and sufficient amount of specific greenhouse gases emissions as well. That's why the implementation of highly effective hot-water boilers with high-efficiency rates above $92-93 \%$ in Kazakhstani heat power engineering, in which up to $40 \%$ of all resources are primary fuel resources, becomes more and more important and demanded in economical and ecological terms. Substitution of more than 130 hot-water boilers with medium capacity, such as PTVM-30M, PTVM-50, PTVM-100 and some boilers of KV-GM series, by new effective hot-water boilers with high efficiency rates across the whole Republic of Kazakhstan would allow to save up to half million tons of reference fuel per year and sufficiently decrease specific emissions of toxic and greenhouse gases.

Authors conducted a wide literary and patent analysis of the possibilities to improve the energy efficiency of boilers. Authors systematized all important works and researches in this field of energy improvement and construction modernization of boilers. Authors developed a new horizontal oriented construction of KV-GM-55150 hot water boiler with high energy efficiency level.

\section{Reliability and energy efficiency analysis of PTVM hot-water boilers}

Rated efficiency of PTVM boilers operated on fuel oil and under nominal load is less than $87 \%[1,2,3]$. The biggest difficulties arise during the operation of the boiler on sulfur fuel oil due to the corrosion of screens and convective part caused by sulfuric acid, which action is enhanced even more by often washes of heating surfaces and build-up of ash residue in the convective part. Because of the sulfur acid corrosion, the service life of PTVM-100's convective part is limited and equals to 2-3 years.

Operational experience, research works and testing of PTVM-100 hot-water boilers have shown that these boilers have some design imperfections, which cause low-reliability rates of heating surfaces and limitation of 
the applied load. Low reliability, in it's turn, causes the increase of repair works and operational costs. Operational disadvantages may be divided into structural, design and operational types, mainly connected with violation of furnace, water-chemical and hydraulic conditions $[1,6,7,8]$.

According to the design, this type of boiler is equipped with 16 fuel oil-fed burners, located on sidewalls, 8 burners in the lower part and 8 more burners in the upper part. Each burner has it's own fan. Analysis of testing the air ducts of burners in boiler installed at st.No.4 of Almaty CHP-1 performed by authors has shown that the efficiency rate of fans differs significantly. The average rate of air consumption per air duct is 2.23 $\mathrm{m}^{3} / \mathrm{sec}$. Non-uniformity of the air supply at certain burners equaled to $25 \%$. This fact is confirmed by the results of other research works. Measured efficiency of certain fans, given in works [8,9] differ by $20-25 \%$ (from 2.36 to $3.06 \mathrm{~m}^{3} / \mathrm{sec}$ ).

Thermal stress of the furnace chamber of PTVM-100 boiler equals to around $580 \mathrm{~kW} / \mathrm{m}^{3}$. Authors assume that short period of time, which fuel spend in furnace under excessive load, rapid cooling of gases in convective section, lack of air pre-heating system and it's injection into the furnace with low speed - are all considered to be conditions of for soot and ash formation in furnace as well as on convective heating elements. Such deposits tend to absorb sulfuric anhydride [1, 10, 11]. According to researches $[11,12]$ the analysis of deposits shows more or less the following content of substances: carbon - 50$70 \%$, ashes $-30-50 \%$, the content of free $\mathrm{H}_{2} \mathrm{SO}_{4}$ is up to $6 \%\left(\mathrm{SO}_{3}-47 \%\right)$. Ash and soot deposits are very sticky, that's why during the use of boilers one may observe the increased formation of deposits on surfaces of the convective pack. Along with that, heat exchange rate decreases, which leads to an increase of temperature of exhaust gases, increase of draft-pressure in convective pack and limitation of load conditioned by draft (lack of vacuum). In case of the natural draft (individual or group smoke duct) the constant operation of boilers under maximum load lasts not more than 6-7 days, in some cases - only 2-3 days. If there is no opportunity available for stopping the unit in order to clear it, then the temperature of exhaust gases rises up to about $573.15 \mathrm{~K}$, and according to certain data [9, 11], 10 days later the boiler's efficiency decreases by almost $50 \%$ from the nominal value. Moreover, instead of the vacuum, there is an excessive pressure building up in the upper section of the boiler.

By the end of the period between washes, the temperature of exhaust gases would exceed the rated value by $333.15-373.15 \mathrm{~K}$ in average, and heat losses with exhaust gases would be $4-7 \%$ higher than rated values. The duration of inter-wash procedures for PTVM boilers depends on the intensity of deposits build-up on convective heating surfaces, which in it's turn depends on the operational load and type of the fuel used. The higher a load of the boiler would be, the more intensive build-up of deposits would be observed. According to the research data $[9,12,13]$, inter-wash period under 40-50\% load from nominal value is $8-10$ days, whereas the same period under $70-80 \%$ load would be 5 days.
PTVM tower hot-water boilers usually obtain damage in the convective section, mainly due to the corrosion $[8$, $10,11]$. A complete substation of the convective section is performed on the most of the boilers after 5000-7000 hours of operation. Damage of screen tubes due to the external sulfur acid corrosion is observed later, about approximately three years of operation. Complete substitution of screen tubes is performed after 10000 11000 hours of operation.

Average costs of such repair works for hot-water boilers installed at several CHPs and boiler houses are higher than for steam boilers, type BKZ-160-100, which have the similar thermal capacity [13]. It should be noted that the annual repair of convective heating surfaces of a single PTVM-100 boiler requires about $14000 \mathrm{~kg}$ of tubes.

In order to increase the operational reliability of convection section on several boilers, there was performed a reconstruction of the convective section, which included the use of a thick-wall tube with larger diameter and increase of the clear opening for gas passage. During the reconstruction, there were used tubes with a diameter of $32 \times 4 \mathrm{~mm}$ and $38 \times 3,5 \mathrm{~mm} \mathrm{[1]}$.

The boiler installed at st.No.4 of Almaty CHP-1 undergo reconstruction of it's convective section according to the project of Special Design Agency of AllRussia Thermal Engineering Institute. The heating surface after reconstruction was equal to $2743 \mathrm{~m}^{2}$, which is $217 \mathrm{~m}^{2}$ less than the factory value. It was calculated that such change should have caused the increase of exhaust gases temperature in comparison to the factory values and be equal to about $543.15 \mathrm{~K}$.

As the result of convective pack reconstruction, it was possible to achieve long-term operation of the boiler under $81 \mathrm{MW}$ without limitations on draft, whereas the traditional design of convective packs has a problem of deposits formation in between tubes due to the small gap between those tubes.

However, authors performed the analysis of statistic data, which considered the exhaust gases' temperature increase and thermal capacity increase in time, related to the reconstructed boiler, installed at st.No.4 (figure 1), and that analysis has shown that under the load of 81 MW and after the wash of the boiler, the temperature of exhaust gases was equal to $463.15 \mathrm{~K}$ but 10 days later temperature has reached the point of $573.15 \mathrm{~K}$ (increase of temperature by $10-11 \mathrm{~K}$ a day). Despite the significant temperature growth, there were no limitations in terms of the draft. And after the second partial wash, the temperature of exhaust gases has significantly decreased, however, it has again reached 573.15 K mark 3-4 days later. 


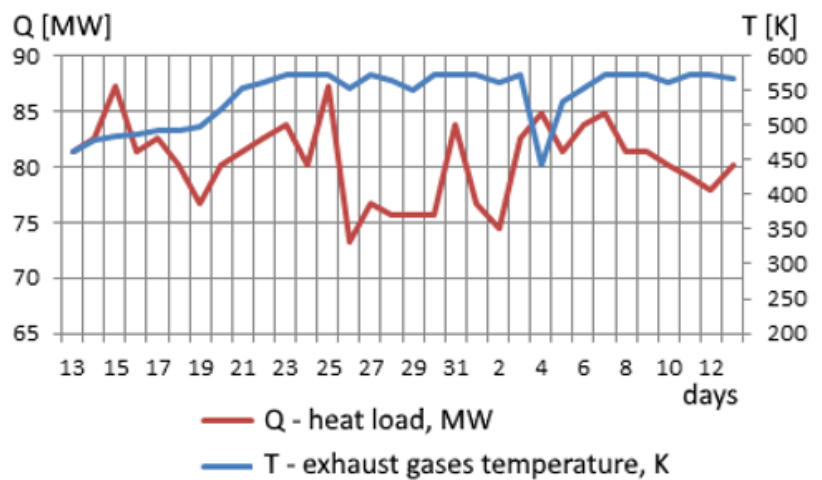

Figure 1. Dynamic of change the heat output and temperature of exhaust gases on the st. №4 boiler Almaty CHP-1 (JanuaryFebruary).

On the st.№2 boiler operated in the middle load of 75.6 MW/h temperature increase velocity was $11 \mathrm{~K} /$ day. Temperature rise velocity is approximately the same. By the clean heating surfaces exhaust gases temperature on the st.№4 boiler higher in 15-20 K that can be explained by decreasing of area of the convective heating surfaces in $217 \mathrm{~m}^{2}$. Analysis shows that reconstruction helps to eliminate the restrictions on thrust but didn't solve the problem with inter-washing period [4].

Boiler tests show that in all load range the boiler efficiency rate was between $87.1 \%$ and $88.5 \%$ with an air excess rate of 1.25-2.17 and exhaust gases temperature of 438.15-543.15 K.

Showed low efficiency is because of next reasons: significant air excess rate, discrepancy between the performance of blowers and fuel oil injectors, increase of exhaust gases temperature due to the decrease of area of the convective heating surface and the introduction of their furnace black-up. If approximate on the values of load close to $100 \%$, temperatures will increase to the level $613.15-623.15 \mathrm{~K}$, and the efficiency will drop to a level 83-84\% [6].

In addition to works carried out on the boiler st.№4, the reconstruction was carried out on the hot-water boilers st.№1 and st.№3 according to the design of SKB VTI [1] with an increase in the volume of the furnace from 245 to $275.3 \mathrm{~m}^{3}$ and increase of the screens surfaces on $20 \mathrm{~m}^{2}$, a change in the burners tilt downwards relative to the horizontal plane by $15^{\circ}$ and the replacement of the upper burners (№ 2, 3, 13, 14) down on $0.7 \mathrm{~m}$ under the main burner tier. Provided on the clean heating surfaces st. № 1 boiler tests show that gross boilers efficiency rate is equal $89.3 \%$ by the load of $116.3 \mathrm{MW} / \mathrm{h}$, exhaust gases temperature $507.25 \mathrm{~K}$, by working 16 burners and fuel oil pressure level of $1.76 \mathrm{MPa}$ and temperature of 413.15 K. Normalized $\mathrm{NO}_{\mathrm{x}}$ output (at air excess rate of 1.4) didn't exceed $0.385 \mathrm{~g} / \mathrm{m}^{3}$. But in long operation period there is also was rise of exhaust gases temperature and decrease of boiler efficiency rate. The main contribution to the reduction in the efficiency of the boiler is made by losses with exhaust gases, which directly depend on the temperature of the exhaust gases, which increases strongly when the heating surfaces are drifted with furnace blacks.

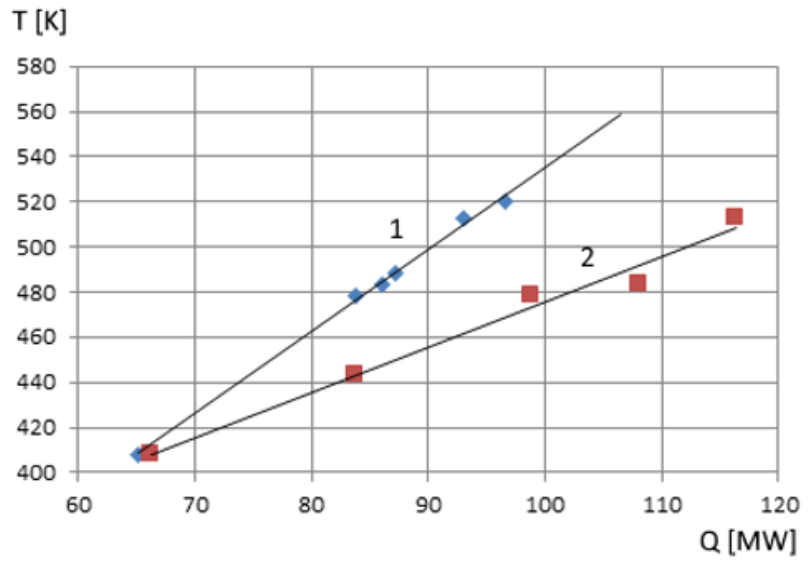

Figure 2. Results of exhaust gases temperature measurements by different load levels of hot-water boiler $(1$ - blacks covered heating surfaces; 2 - clean heating surfaces).

By the load of $80-85 \%$ of the nominal level temperature rises up to $513.15 \mathrm{~K}$. Figure 2 shows comparison of exhaust gas temperature rise for clean and blacks covered heating surfaces.

As can be seen from figure 2, the temperature increase for blacks covered heating surfaces is so strong that when extrapolated to a load close to the nominal level, the temperature would be about $573.15 \mathrm{~K}$. The boiler efficiency would be reduced to $85 \%$. The convective heating surfaces furnace black-up causes the aerodynamic resistance increase which leads to a lack of draft. Therefore, during operation on fuel oil, the heating capacity of the boilers is not raised to the nominal and the operating parameter tables are up to $70-80 \%$ of the nominal load.

Such analysis of PTVM-100 reconstruction results has shown that technical and economic indexes of improved boilers didn't change much $[1,4,6]$.

On-model calculations of PTVM-100 boiler, conducted by authors using the BOILER DESIGNER [1, 14] software, have shown that outlet furnace temperature during operation on gas in peak mode equals to 1657.15 $\mathrm{K}$, and during operation on fuel oil $1597.15 \mathrm{~K}$.

\section{Analysis of technologies used for the reliability and energy efficiency increase of medium capacity PTVM and KVGM hot-water boilers}

Figures Today, boiler factories, as well as various design and scientific organizations, are looking for technical improvement of hot-water boilers, and design of new boilers. Yet, the preference is given not to the construction of new boiler houses, which requires great funds, but to the modernization or reconstruction of already existing units, which would increase boilers' reliability, industrial safety and ecological indexes of units without enlargement of areas of thermal stations and boiler houses along with saving the resources, economy of consumed energy and operational costs.

Based on the years and years of monitoring of installed equipment, and with consideration of the cutting edge technologies, specialists from JSC 
"Dorogobuzhkotlomash" have developed the program, which offers the series of actions aimed at the improvement of KVGM and PTVM series hot-water boilers $[1,5,13]$.

By this time, JSC "Dorogobuzhkotlomash" has designed, tested and implement various types of modernization/reconstruction options, practical results from which have shown dozens of realized projects at large-scale heat supply facility systems, and at about hundred improved boilers with 50MW capacity and above.

Main implemented events on the modernization of PTVM type boilers can be reduced down to the following: increase of furnace volume; an increase of a number of the section in convective part while preserving the same overall dimensions; installation of new gasoperated burners with recirculation units; substitution of air ducts and blowing fans $[1,15]$.

During the development of solutions on modernization/reconstruction of boilers JSC "Dorogobuzhkotlomash" has paid a special attention to the improvement of ecological indexes of the produced equipment. Thus, based on the design of PTVM-60 and PTVM-120, there were created a new type of boilers PTVM-60E and PTVM-120E. Design of these boilers underwent several manipulations aimed at the decrease of harmful emissions rate (installation of the bi-radiated screen and two-row arrangement of burners for an increase of heating surface and a decrease of torch temperature) $[1,5,15]$.

Such improvement allowed to decrease nitrogen oxide $\left(\mathrm{NO}_{\mathrm{x}}\right)$ emissions to the level of $0.1-0.11 \mathrm{~g} / \mathrm{m}^{3}$, which is less than required by European regulations. Along with the improvement of ecological indexes, PTVM-E boilers show the increase of efficiency rates by $2 \%$ [13].

One more area of reliability and efficiency increase of hot-water boilers realized at JSC "Dorogobuzhkotlomash" is the reconstruction of serialproduction-boiler KV-GM-116,3-150 (KV-GM-100) and using this model as the basis for the creation of the new KV-GM-139,6-150 (KV-GM-120) boilers [1, 15].

JSC "ZiO-Podolsk" and JSC "Engineering Company "ZiOMAR" are also designing an equipment for modernization of large PTVM and KVGM type hot-water boilers $[12,13]$.

The basis for modernization of large hot-water boilers is represented by recent achievements in design and production technologies, which came from the sphere of global energetics, and which provided the implementation of new technical solutions that satisfy market demands the most. For the modernization of large hot-water boilers of PTVM and KVGM type, there are the following elements required:

- Convective heating surface made of tubes with increased diameter and wall thickness ( $\mathrm{d} 38 \mathrm{x} 4 \mathrm{~mm}$ tubes) with external fins,

- tubes with increased diameter, external longitudinal and transverse fins,

- low-toxic swirl burners with increased individual capacity operated on fuel oil or gas,

- comprehensive fans with great individual capacity,
- systems of combustion products recirculation for fans used for the decrease of nitrogen oxide emissions and pre-heating of the blown air till the positive temperature, in case of gas operated boilers, and calorific units used for pre-heating of the inlet air till the temperature of 333.15-353.15 K, in case of fuel oil operated boilers,

- system of fuel combustion control, which provides safe use of equipment installed at the boiler house.

In order to substitute the PTVM type boilers installed at large boiler houses, a subsidiary of KCDO "Energoprogress" has design boilers of KV-G series [13]. KV-G-34,9-150, KV-G-58,2-150 boilers are installed into the boiler spots of already existing PTVM-30 and PTVM50 boilers accordingly. KV-G-116,3-150 boiler has a bit bigger dimensions on column axes, and if there is no free space for installation, the unit may be installed on the place of the boiler, which is located near the temporary gable façade of the boiler house, however, such installation requires the construction of additional $3 \mathrm{~m}$ of the building.

Solutions for the modernization of boilers PTVM aimed: at solving the constructive and circuit problems, improving the reliability and efficiency, at the elimination of restrictions on the load and improving environmental performance without any changes in the dimensions of the montage slots of existing boilers.

Authors suppose that technical solutions used for reconstruction of the hot-water boiler may be borrowed from the experience of boilers development in the sphere of global energetics. The base of it consists of all-welded membrane screens, convective surfaces of the membrane, and tubes with transverse band fins and multi-channel swirl burners with increased individual capacity operated on fuel oil and gas.

KV-GM-100-150S earthquake-proof hot-water boiler with a thermal efficiency of $116 \mathrm{MW}$, designed and manufactured by Belgorod factory called "Energomash" in conjunction with VTI institute specialists and NPO CKTI specialists, includes gas-proof furnace design and all-welded membrane panels for convective pack sections.

Tests of this boiler have shown it's high rate of efficiency during the operation on gas - 93,7\% - and during the operation on fuel oil $-92,7 \%$. The temperature of exhaust gases during the operation on gas was equal to $398.15 \mathrm{~K}$ and $427.15 \mathrm{~K}$ during the operation on fuel oil.

Besides the recommendations on reliability and efficiency of PTVM and KVGM hot-water boilers given above, in works $[9,12,13]$ there was also described the importance of the organization of effective combustion regime with the use of up-to-date burners. It is suggested to decrease the number of burners installed on boilers to 4-6 units, moreover, all of the burners should be installed on one and the same side of the furnace.

Speaking about the PTVM type tower boilers, the most important task during boiler's operation on fuel oil - is the decrease of rates of soot and ash deposits formation on convective heating surfaces, and this task may be solved by the use of bi-radiated screens and convective packs with a larger transverse gap. 


\section{Research works and designs offered by authors for an increase of reliability and energy efficiency rate of medium capacity PTVM and KVGM hot-water boilers}

Authors of this articles have suggested design solution, which differs from all previous types of PTVM-100 modernization works, and includes the use of bi-radiated screens $[1,4,6,16]$. After the implementation of the suggested solution, the radiant heating surface of the furnace in an improved boiler increases by $246 \mathrm{~m}^{2}$. The relation of radiant surface to convective surface is increased up to $15,8 \%$, whereas old PTVM-100 boilers the same relation was only 7,5\%. Model-based calculations of improved PTVM-100 boiler, conducted by authors using the BOILER DESIGNER [1, 14] software have shown that the temperature of gases in the furnace outlet area and before convective packs has decreased by $423.15 \mathrm{~K}$, moreover, in such case convective packs are able to operate in more favourable thermal conditions, just like in hot-water boilers with $\Pi$ shape design $[4,7]$.

Proposed by authors changed construction of the convective pack $[17,18]$ helps increase boilers efficiency rate by operating on the fuel oil up to $90.49 \%$ (on load of $116.3 \mathrm{MW} / \mathrm{h})$. It is $3 \%$ more than the traditional constructions can give. Calculations were carried out for the most adverse conditions of operation of the hot-water boiler at the air temperature at the inlet to the burner equal to the design temperature of the outside air of $252.15 \mathrm{~K}$. Efficiency rates of boilers could be higher by inside of the boiler room placement and preheat of the inlet air.

It was also suggested to install two-row bi-radiated screen that wraps around the furnace and has the height of $0,63 \mathrm{xH}_{\mathrm{f}}$ (where $\mathrm{H}_{\mathrm{f}}$ is the height of the furnace), but the key is to install it 1.8-2.2 $\mathrm{m}$ before the reversing screen of the new KV-GM-55 hot-water boiler with the horizontal design. One more suggestion was to arrange two closely located convective sections with $\varnothing 32 \times 3 \mathrm{~mm}$ tubes in a new way - in the gas duct located behind the screen. In this new arrangement of two convective sections, both of the sections have the counter-flow type of a system for water flow and for the flow of the combustion products, which allowed maintaining high level of thermal pressure and the corresponding thermal output of gas flow towards the tubes along the whole height of two convective pack of tubes. The speed of water in each water passage of convective tubes was changed by means of varying the number of tube rows per pack, and by the speed of the gas flow. Technical parameters of a boiler with the new design were improved in order to reach the following characteristics: radiant heating surface equals to $\mathrm{H}_{\mathrm{r}}=$ $286,7 \mathrm{~m}^{2}$; convective heating surface equals to $H_{c}=1406$ $\mathrm{m}^{2}$; furnace volume $\mathrm{V}_{\mathrm{f}}=313,3 \mathrm{~m}^{3}$. The installation of the additional two-row wrapping screen before the reversing screen, located at the end of the furnace, allowed to increase significantly heating characteristics of the boiler due to the intensification of heat exchange, and to decrease the temperature of exhaust gases along with the increase of boiler's efficiency rate $[3,4]$. Testing results of the KV-GM-55 (st.No. 5) installed at "Akselkent: boiler house, Almaty city, which were obtained by specialists of LLP "ATKE" are shown in Table 1

Table 1. Results of thermal and technical testing of KV-GM-55 (st.No.5) installed at "Akselkent" boiler house, Almaty city, under operational load.

\begin{tabular}{|c|c|c|}
\hline Parameters & Mode 1 & Mode 2 \\
\hline Thermal efficiency, MW & 45.79 & 49.6 \\
\hline Gas pressure at burner, $\mathrm{kPa}$ & 13.63 & 16.37 \\
\hline $\begin{array}{l}\text { Boiler water consumption, } \\
\text { tons/hour }\end{array}$ & 658 & 658 \\
\hline Air pressure at burner $(\mathrm{kPa})$ & 1.73 & 2.04 \\
\hline Water inlet temperature, $\mathrm{K}$ & 336.15 & 336.15 \\
\hline Water outlet temperature, $\mathrm{K}$ & 123 & 128 \\
\hline $\begin{array}{l}\text { Gas consumption, by } \\
\text { instrument, } \mathrm{m}^{3} / \mathrm{sec}\end{array}$ & 1.41 & 1.55 \\
\hline $\begin{array}{l}\text { Boiler's water pressure } \\
\text { resistance, } \mathrm{kPa}\end{array}$ & 350 & 350 \\
\hline $\begin{array}{c}\text { Efficiency rate, by indirect } \\
\text { heat balance, } \%\end{array}$ & 93.06 & 92.86 \\
\hline Cold air temperature, $\mathrm{K}$ & 288.15 & 288.15 \\
\hline $\begin{array}{c}\mathrm{O}_{2} \text { content in released gases, } \\
\%\end{array}$ & 3.5 & 3.2 \\
\hline Furnace draft, $\mathrm{kPa}$ & 0.03 & 0.03 \\
\hline $\begin{array}{l}\text { The temperature of released } \\
\text { gases, } \mathrm{K}\end{array}$ & 420.15 & 427.15 \\
\hline $\begin{array}{l}\text { Heat losses due to released } \\
\mathrm{q}_{2}, \%\end{array}$ & 6.38 & 6.63 \\
\hline $\begin{array}{l}\text { Heat losses due to emitted } \\
\text { combustibles } \mathrm{q}_{3}, \%\end{array}$ & 0 & 0 \\
\hline $\begin{array}{c}\text { Environmental heat losses, } \\
\mathrm{q}_{5} \%\end{array}$ & 0.56 & 0.51 \\
\hline $\begin{array}{l}\text { Specific consumption of } \\
\text { reference fuel, } \\
\text { kg.ref.ton/MW }\end{array}$ & 178.9 & 1183.54 \\
\hline $\begin{array}{l}\text { Gas heat output, } \mathrm{Q}_{\mathrm{H}}, \\
\mathrm{MW} / \mathrm{m}^{3}\end{array}$ & 34.68 & 34.68 \\
\hline
\end{tabular}

6 modern KV-GM-55 and KV-GM-35 of authors' construction have been successfully operating since 2012 without any deformations, leaks and water condensation on the surface of furnace screens. The efficiency rate according to the regular tests is on the high level.

\section{Conclusion}

The analysis of experimental and theoretical data about conducted in Kazakhstan reconstruction and modernization of PTVM-100 boilers showed that the reconstruction of PTVM-100 boilers carried out at the 
CHP and boiler houses is aimed more to improving the reliability, while the efficiency of the boilers remained almost at the same level.

Presented calculations show that the modernization of the boiler PTVM-100 installation of two bi-radiated furnace screens and modernization of the second convective pack can significantly improve the reliability of the convective surfaces, increase the productivity of the boiler to $145 \mathrm{MW} / \mathrm{h}$ and efficiency to $92.35 \%$ when operating on natural gas and $89 \%$ when operating on fuel oil. At a load of $116.3 \mathrm{MW} / \mathrm{h}$ boiler efficiency was $92.58 \%$ (on natural gas) and $90.5 \%$ (on fuel oil) which is much higher than the normative characteristics of the boiler PTVM-100.

The installation of two-row bi-radiated screen wrapping around the furnace and the new arrangement of two, located next to each other, convective parts with $\varnothing 32 \times 3 \mathrm{~mm}$ tubes in the gas duct area behind the screen, provided the significant increase of boiler's heating output rates due to the intensification of heat exchange and to lower the temperature of gases released behind the boiler along with increase of unit's efficiency rate up to $92,5 \%$ under nominal load.

\section{References}

1. R.K. Orumbayev, Khodanova T.V., Kibarin, A.A, Korobkov M.S. 2018. Efficiency assessment of bi-radiated screens and improved convective set of tubes during the modernization of PTVM-100 tower hot-water boiler based on controlled all-mode mathematic models of boilers on Boiler Designer software // IOP Conference Series: Earth and Environmental Science, volume 136, 2018. paper ID 012016

2. V.I. Vasilyev 1974. About heat exchange in KVGM boiler operated on sulfur fuel oil // Power energy employer. №10., - p.12.

3. Orumbayev, R.K., Orumbayeva, Sh.R., 2005. Economical and ecological effect during the replacement process of hot-water boilers across the Republic of Kazakhstan // Actual Problems of Economics. ISSN - 19936788. Kiev. No.5. p.38-43.

4. R.K. Orumbayev, V.V. Sergeev, A.A. Kibarin, Sh.R. Orumbayeva, T.V. Khodanova, M.S. Korobkov 2015. Improvement of efficiency and reliability of PTVM-100 tower hot-water boiler // Bulletin of AUPET № 4(31)., - pp.11-19.

5. V.A. Ovchinnikov, S.A. Petrikov, A.K. Krylov 2011 Best exploitation practices of hot-water boilers at OAO Dorogobuzhkotlomash / Heat engineering - No.12. - p.22-46.

6. R.K. Orumbayev, A.A. Kibarin, Sh.R. Orumbayeva, T.V. Khodanova, M.S. Korobkov, A.K. Mergalimova 2015 Proposals of increasing of economical efficiency and reliability by
PTVM-100 tower hot-water boilers modernization // Energetics. Efficiency, reliability, safety: Proceedings of XXI all-Russia scientific-technical conference 2-4 Dec. TPU, Tomsk. - "Scan" publ. - 1T. - pp.399-402.

7. Information letter № 5-80, 1980. Change of hydraulic scheme of heating surfaces of PTVM gas-fuel oil hot-water boilers with aim to increase their reliability // $\mathrm{M}$.: $\mathrm{SPO}$ Soyztechenergo.

8. I.A. Aksencov, Y.P. Zaykov 1974. PTM-100 operating on natural gas combustion mode setting // Power energy employer № 5. - pp.3133.

9. E.L. Bilkis, N.I. Zhirnov, V.A. Zaycev 1968. Study of the operation of PTVM-100 the peak hot water boiler on high-sulfur fuel oil // Power plants № 3. - pp.27-30.

10. V.M. Sobolev, D.B. Achmetov 1981. Calculation of the burning of heavy liquid fuels with multistage combustion // Heat power engineering № 5. - pp.40-44.

11. E.E. Laykovsky, R.I. Sorokin 1973. Discharge of the convective pack of the PTVM-50 boiler // Industrial heat power engineering № 3. pp. 25-26.

12. I.M. Mesheriyakov, G.V. Vasilenko, G.M. Bovina, V.M. Borovkov 2007. Improving the efficiency of operational cleaning of hot water boilers // Heat power engineering № 9. pp.70-72.

13. Zhuravov, A.A., 2000. Reconstruction of PTVM-100 and PTVM-50 boilers - real solution of lack of heat capacities and heat supply in city. // Heat supply news. No.1., - p.22-23.

14. Doverman, G.I., Moshkarin, A.V., Shelgin, B.L., Melnikov, Y.V., 2007. Design calculations of boiling units using modern software: study guide / SEIHE "Ivanovo state university of energetics named after Lenin V.I.". - Ivanovo.

15. Dorogobuzhkotlomash, 2007. Catalogue of hotwater boiler with low capacity from 11,63 to 209 $M W$. Vol.2. 4 edition. - p.79.

16. Orumbayev, R.K., Orumbayeva, Sh.R., Kibarin, A.A., Orumbayev, A.R., 15.07.2015. "Hotwater boiler": Innovative Patent RK No.30150 / Rep. No. 7.

17. Orumbayev R.K., Orubmayeva Sh.R., Kibarin, A.A., Khodanova, T.V., 2017. "Convective tubes pack": Patent RK for invention No.31833 / Rep. No.2.

18. Orumbayev R.K., Orubmayeva Sh.R and others 2018. "Hot-water boiler" : Patent RK for utility model №2864 / Rep. №21. 